\title{
O CORREIO BRAZILIENSE (1808-1822), O ENSINO MÚTUO E O DESENVOLVIMENTO MATERIAL DO BRASIL
}

\author{
Marcília Rosa Periotto \\ Universidade Estadual de Maringá
}

\section{RESUMO}

Este estudo integra a pesquisa de pós-doutorado cujo tema é o jornal Correio Braziliense, publicado por Hipólito da Costa em Londres entre os anos de 1808 a 1822, realizado com o objetivo de vinculá-lo à educação política da elite brasileira nas décadas iniciais do século XIX. Ao difundir o ideário liberal no Brasil, o jornal marcaria o processo de separação política entre colônia e metrópole e influenciaria os brasileiros a reivindicarem maior participação nas decisões do governo e o mesmo tratamento dispensado aos portugueses. A proposta feita por Hipólito da Costa de adoção do ensino mútuo no Brasil, entre outros objetivos, buscava difundir o saber dos imigrantes estrangeiros e instalar os conteúdos necessários ao seu desenvolvimento material. A d. João aconselhava substituir os braços escravos pelos trabalhadores estrangeiros livres, permitindo a entrada dos mesmos no território brasileiro e oferecendo-lhes, em contrapartida, condições para adaptação e amparo das famílias. O Correio incluía a educação de "todos a todos" como um dos pilares do processo civilizatório, fundamental ao progresso material que se pretendia estabelecer. Palavras-chave: Correio Braziliense, Ensino Mútuo, Brasil-Século XIX, Imprensa.

\section{THE CORREIO BRAZILIENSE (1808-1822), THE MUTUAL EDUCATION AND BRAZIL'S MATERIAL DEVELOPMENT}

\begin{abstract}
This study integrates the post-doctoral research whose theme was the Correio Braziliense newspaper, published by Hipólito da Costa in London, from 1808 to 1822, created with the objective of connecting with the political education of Brazilian high class society from the early $20^{\text {th }}$ century. By disseminating the liberal ideals in Brazil, the newspaper would Mark the process of political separation between colony and metropolis and would influence the Brazilians to demand more significant participation in government decisions and the same treatment granted to the Portuguese. Hipólito da Costa's proposal of adopting the mutual education in Brazil, among other things, aimed at spreading the knowledge of the foreign immigrants and settling down the necessary content to its material development. To D. João, he advised the substitution of the manual labor of slaves by the work of free foreigners, by allowing their entrance in the Brazilian territory and offering conditions for their adaptation and support to their families. The Correio included the education of "all to all" as one of the pillars of the civilizing process, key to the material progress intended to be established.
\end{abstract}

Keywords: Correio Braziliense, Mutual Education, Brazil-20th Century, Press.

\section{Introdução}

O estudo do jornal Correio Braziliense vinculado à História da Educação permite analisar o processo de formação da consciência da elite brasileira nas primeiras décadas do 
século XIX. Junto às questões de cunho político e econômico, debatidas no jornal, encontra-se uma sugestão de adoção do ensino mútuo feita a d. João VI como uma das vias para a realização das relações burguesas no Brasil.

Desde que Mecenas Dourado (1956) e Carlos Rizzini (1957) publicaram biografias sobre Hipólito da Costa, amparadas em fontes documentais colhidas na Inglaterra numa longa busca nos arquivos públicos, pessoais e paroquiais, o interesse pelo autor do Correio Braziliense e pelo jornal expandiu-se. São vários os estudos elaborados sobre ambos, os quais abordam aspectos variados do Correio ou buscam perscrutar a figura de Hipólito da Costa tentando compreender os móveis que o levaram a inaugurar um jornal opositor à proeminência da aristocracia portuguesa na administração do reino, bem como traçar um projeto de desenvolvimento social para o Brasil assentado no modelo inglês.

Ao estudo interessou captar o caráter educativo das ideias dispostas no projeto de desenvolvimento e nos embates políticos realizados no jornal, e das influências exercidas na formação da consciência da elite brasileira daquele período. O liberalismo inglês, presente no quadro de propostas defendidas no Correio, coadjuvado ao ideário libertador emanado da Revolução Francesa naqueles temas que não romperiam com a tradição monarquista, pode então penetrar de forma organizada e sistemática, e como parte de um grande esforço teórico, na consciência da camada economicamente dominante e guiá-la para o advento da independência, não obstante se reconheça não ter sido tarefa essa exclusiva ao Correio.

O Correio Braziliense surgiu num contexto político adverso ao sistema de governo português. A vinda da família real e da corte para o Brasil evidenciava uma série de percalços enfrentados pela Coroa, avantajados pelo declínio da metrópole e estimulados por medidas governamentais cegas às transformações da época e persistentes na manutenção do mercantilismo como fonte de riqueza.

Conhecedor da pujança inglesa e do resultado da aplicação dos novos princípios da economia na esfera da produção, Hipólito da Costa via na educação política da elite a possibilidade de interferência na realidade colonial brasileira e de atendimento das necessidades trazidas pelo desenvolvimento das forças produtivas burguesas. Ilustrado e defensor da aplicação imediata dos princípios liberais creditava à ação da imprensa a característica de papel educativo, convicto de que esse era um meio ideal de difusão dos conhecimentos demandados pelas sociedades progressistas, insistindo na correta aplicação das práticas que faziam as nações poderosas e alheias aos costumes incivilizados, prejudiciais à acumulação e produção da riqueza.

O expediente sugerido por Hipólito da Costa para contestar o domínio da aristocracia na administração do reino contava com a divulgação dos saberes e da crítica política contra os indivíduos que agiam inadequadamente no comando do Estado, porquanto inaptos na condução dos negócios e ignorantes nos conteúdos requeridos na prática do comércio entre nações. $\mathrm{O}$ desconhecimento dos novos trâmites comerciais e uma diplomacia tacanha submetia os interesses da Coroa aos dos ingleses, como no episódio do aprisionamento dos vasos portugueses no qual a falta de visão política e subserviência dos ministros portugueses, no caso o Conde de Linhares, d. Rodrigo, concordou em estipular no tratado de 1810 a direito da Inglaterra de confiscar os vasos da esquadra portuguesa que eram de construção estrangeira, isto num momento em que se sabia que a frota era praticamente toda construída fora de Portugal (CORREIO BRAZILIENSE, 2001, v. VI, p.43-46).

Em razão de atitudes inaptas da diplomacia, e do constante prejuízo dos interesses comerciais portugueses, Hipólito da Costa reivindicava um tipo de formação intelectual a 
qual os homens de Estado e de negócios não podiam nem desconhecer e nem abdicar sob pena de deixar de ser Governo:

Mas suponhamos, por argumento, que essa fraqueza dos portugueses é tal qual esses homens a representam; nesse caso, se a nação não pode sustentar a sua independência, deixem de ser governo Soberano, metamse debaixo da tutela de alguma potência que tenha forças para os proteger e que possa sustentar os seus direitos de homens livres. Mas que este argumento da pequenez de Portugal é meramente uma capa com que os ministros procuram encobrir a sua ignorância e o não saberem manejar os negócios de que se encarregam se vê claramente no exemplo presente (CORREIO BRAZILIENSE, 2001, vol. VI, p. 43-46).

Hipólito da Costa reconhecia esse modo de agir como prejudicial à Coroa e o contradizia com os termos de conduta que os homens pródigos deveriam adotar na condução dos negócios de Estado, amparados nas regras burguesas, definindo-os como a ciência necessária ao governo:

É, portanto, a ciência do Governo, a ciência de fazer os homens felizes: e como a felicidade se compõe de elementos diversos, ainda se pode definir, o conhecimento dos meios de procurar aos Povos a maior massa de liberdade, de segurança, de tranqüilidade, e de virtude; de riquezas, de saúde, e de forças, que for possível que eles gozem simultaneamente. Vejo na ciência do Governo dois ramos importantes, cada um dos quais se subdivide em uma quantidade de ramos menores; um tem por objeto os princípios de sua constituição, e o outro as regras de seu comportamento. O primeiro pelo estabelecimento da verdadeira liberdade eleva o caráter do cidadão à grandeza, à nobreza e à virtude, ao mesmo tempo em que pelo firme estabelecimento da ordem, provê a sua segurança e ao seu repouso: o segundo, pela adoção de uma sábia legislação econômica e financeira faz florescer as artes, o comércio, e a agricultura, elevando assim a nação, por meio da riqueza e do poder, ao mais alto grau de prosperidade (CORREIO BRAZILIENSE, 2001, v. I, p. 340).

O quadro deficitário na acumulação e manutenção da riqueza decretava que se adotassem ações imperativas capazes de conter o agravamento da pobreza econômica e social do reino, as quais nunca eram tomadas satisfatoriamente já que Portugal rechaçava as práticas produtivas avançadas e mantinha-se atrelado ao mercantilismo.

A existência de um jornal nos moldes do Correio Braziliense incomodava o governo e a aristocracia ao ponto de ser proibido por meio do édito público assinado por d. Rodrigo de Sousa Coutinho em 1811, um antes amigo e protetor de Hipólito da Costa e tornado um seu desafeto por forças das circunstâncias. Porém, a polícia real não conseguiu impedir a circulação do jornal entre os brasileiros e portugueses descontentes com a administração e nem que deixasse de espalhar as ideias liberais e conhecimentos que pregava como basilares ao progresso material. Diz Tengarrinha que

Nada mais restava aos jornalistas liberais que se haviam empenhado no debate político durante cerca de dois anos do que retomá-lo no estrangeiro, em condições de maior liberdade que lhes permitiam sair em defesa aberta de uma nova ordem constitucional e criticar duramente a degradante situação nacional. E, desta maneira, não só procurar influenciar os meios políticos e diplomáticos estrangeiros, mas também 
ter algum peso nos centros de decisão de Portugal e Brasil, bem como espalhar as idéias liberais em círculos politizados (TENGARRINHA, 2001, p. 227).

O jornal surtiu efeito. Alegam os historiadores que Hipólito da Costa conseguiu seu intento quando o Correio passou a ser disputado pela elite nos poucos exemplares que chegavam por contrabando, confirmando-se o seu papel auxiliar na incubação de uma consciência predisposta à defesa dos interesses brasileiros. A elite brasileira, rejeitada na esfera política e alijada das decisões, pouco ou sequer ouvida pela administração central, teve que desenvolver ideias que justificassem o seu descontentamento e dessem organicidade aos seus pleitos.

Entre os fatores impeditivos da difusão no Brasil de saberes já em plena expansão nas nações europeias, havia uma quantidade insuficiente de escolas e quando funcionavam as poucas que existiam, prevaleciam os conteúdos inadequados ao desenvolvimento material. O privilégio do saber ler e escrever reduzia-se aos membros da elite, os quais, quando podiam, enviavam os primogênitos à Coimbra e Lisboa a fim geralmente de se formarem em Leis ou então, mesmo raramente, em Medicina.

$\mathrm{O}$ receio dos portugueses quanto à formação educacional dos coloniais não encontrava eco nos retornados, que reproduziam o pensamento corrente na Europa espalhando as ideias de liberdade e igualdade. Esse ideário somou-se às solicitações das camadas socioeconômicos elevados da colônia por mais liberdade nos negócios e maior participação na estrutura política do Reino.

Estabelecer a relação entre estes fatos e o Correio e, por seguimento, à História da Educação, é medida que inscreve o estudo numa perspectiva de análise que prioriza a construção da sociedade brasileira como desdobramentos das relações capitalistas mundiais e nos limites das relações coloniais produziram especificidades as quais devem ser compreendidas no contexto das relações colônia e metrópole. Hipólito da Costa e o Correio Braziliense estão inscritos nesta história como elementos essenciais à separação política entre Brasil e Portugal, e como interpretes de uma época que exigia a instalação definitiva das relações burguesas nas colônias ultramarinas.

\section{A educação e o Correio Braziliense}

A vinculação entre imprensa brasileira e a educação no século XIX, observada nos jornais e folhas do período ressaltam o propósito de difundir a ciência burguesa e as ideias expressivas do desenvolvimento material que impulsionava as transformações sociais na Europa. Essa relação está presente com clareza na Introdução com a qual Hipólito da Costa (1774-1823) inaugurou o Correio Braziliense em 1 de junho de 1808:

Ninguém mais útil, pois, do que aquele que se destina a mostrar, com evidência, os acontecimentos do presente, e desenvolver as sombras do futuro. Tal tem sido o trabalho dos redatores das folhas públicas, quando estes, munidos de uma crítica, e de uma censura adequada, representam os fatos do momento, as reflexões sobre o passado, e as sólidas conjecturas sobre o futuro (CORREIO BRAZILIENSE, 2001, v. I, p. 3).

O Correio realizou alentada crítica contra a administração portuguesa, incapaz, naquele início de século XIX, de empreender uma política de desenvolvimento econômico consonante a um maior aproveitamento das riquezas naturais do Brasil e de solucionar as crises que irrompiam intermitentes no território lusitano. 
O empreendedorismo dos norte-americanos, conexo ao ideário liberal em expansão, presenciado durante a viagem feita por Hipólito da Costa aos Estados Unidos (1798-1799), bem como o avançado progresso material da Inglaterra, visto e vivido nos anos de exílio em Londres (1805 a 1823), o instigaram a defender a aplicação de reformas econômicas e sociais no Brasil e Portugal, fazendo das páginas do Correio um espaço excepcional na exposição de ideias nascidas na observação da potência inglesa. Marisa Saenz Leme assinala que:

Embora tenham numericamente prevalecido no jornal matérias de conteúdo político, os artigos sobre as condições socioeconômicas brasileiras constituíram-se grandemente em exposições bem articuladas dos conceitos que norteavam os posicionamentos do editor da área, configurando-se um "programa para o desenvolvimento do Brasil", conforme indica o título de um deles, publicado em 1816 (LEME, 2004, p.42).

As ideias e propostas expostas no Correio remetem ao esforço de formar nos brasileiros uma visão avançada sobre os procedimentos necessários ao progresso material, de maneira a habilitá-los ao exercício do poder político conjugado aos fundamentos exigidos na construção de um Estado antípoda ao absolutismo português. Nesse contexto, o conteúdo oferecido à instrução dos cidadãos expressa o papel educativo que sobressai na sua obra, cujo teor incentivava levar o Brasil a um quadro favorável de progresso na medida em que incorporasse formas variadas de cultivo e aprimoramento da agricultura, maximizadas pelo aproveitamento das riquezas naturais e cultiváveis.

No contexto da produção material em expansão, a importância da vinda da família real e da corte portuguesa para o Brasil é consenso na historiografia brasileira. Potencializou, diz a maioria dos historiadores, as demandas já existentes em gérmen por maior autonomia política e valorização dos brasileiros, os quais produziam a riqueza da qual Portugal era o maior beneficiário ao manter o direito de negociá-la internamente e com os demais países europeus. Entretanto, não se permite afirmar que a estadia dos lusitanos fugitivos foi motivo sobranceiro no desiderato político entre colônia e metrópole, mas figura com importância entre as causas da separação.

A chegada dos metropolitanos em fins de 1807 comprovou a situação de descaso dispensada aos coloniais. Os resultados de um governo displicente com as necessidades da colônia e de seu povo rapidamente foram sentidos: o Brasil, visto apenas como um grande centro fornecedor de riquezas, nunca desfrutou de um plano mais avantajado de melhorias, as quais, se implantadas, juntamente com uma política de afrouxamento da rígida administração certamente encerrariam, ou postergariam, os desejos de liberdade de um grupo de indivíduos que, excluídos da nobreza e dos privilégios, ressentiam-se da pouca consideração e importância social e política cominadas pelos portugueses.

Preso à condição colonial e a tudo que ela representava em termos de negação das forças avançadas então existentes, o Brasil se ressentia de uma política que permitisse negociar os bens que produzia sem a intermediação dos portugueses. A proibição de tomar parte ativa no mercado de compra e venda de mercadorias e na definição de políticas que efetivamente protegessem os interesses brasileiros produzia uma insatisfação entre a elite, composta por fazendeiros e grandes comerciantes, que somente podiam exercer seus negócios depois de submetidos às regras tarifárias portuguesas, extremamente onerosas e avessas à produção e ao intercâmbio de gêneros.

As inúmeras mudanças operadas na sociedade brasileira não foram capazes de extinguir o sustentáculo da produção da riqueza, o trabalho escravo, que permaneceu 
inalterado até praticamente a passagem para o século XX e em nenhum momento foi posto, de fato, à dura prova de uma radical substituição. As razões históricas dessa permanência se encontram primeiramente na escassez de braços livres disponíveis e na política imposta pela metrópole à colônia, além do tráfico se revelar um expediente de grande lucro e enriquecimento, tornando-se à época uma das atividades comerciais mais rentáveis aos portugueses e holandeses, entre outros povos.

Portugal, por sua vez, não podia praticar a partilha dos recursos naturais com as outras nações para não arriscar perder a fonte de riqueza e sustento das finanças portuguesas. Entretanto, ao longo do processo de colonização muitas concessões foram feitas aos ingleses em troca do apoio e proteção contra as investidas francesas e espanholas, situação que atingiu o ápice nos tratados de 1810 firmados entre d. João VI e a Inglaterra, quando essa resguardou a esquadra portuguesa fugitiva e prontamente cobrou o governo português pelo auxílio prestado.

O fato é que em 1808 os portugueses tiveram a oportunidade de conhecer o Brasil de perto e de verificar as vicissitudes de uma colônia pujante em riquezas naturais, mas pobre em condições melhores de vida. Entre as providências tomadas por d. João logo após $\mathrm{o}$ ato de abertura dos portos, a primeira foi adequar minimamente os meios encontrados às necessidades dos forasteiros e de proporcionar melhorias na cidade que serviria de moradia à família real e à corte portuguesa, e oferecer educação aos filhos da nobreza e dos abastados, que habitualmente compunham a esfera administrativa do reino.

Ana Paula Seco (2004) argumenta que a iniciativa de d. João VI de colocar em prática um plano direcionado à instalação de escolas não obteve sucesso devido a falta de condições e recursos, além de contrariar a metrópole que se opunha a qualquer manifestação de cunho liberal. Medidas que interferissem na manutenção de seus interesses eram totalmente rejeitadas, perpetuando assim a ignorância e apatia da maioria da população.

Dessa forma o século XIX se abriu para o Brasil como uma época em que faltavam escolas, mas, fundamentalmente, um plano de escolarização sistemático que favorecesse a formação dos homens pobre e livres. A educação da elite brasileira apresentava quase sempre caráter doméstico, com as crianças instruídas no âmbito dos lares. Faria Filho assinala que as poucas escolas existentes até a independência funcionavam, "na maioria das vezes, nas casas dos professores ou, sobretudo, nas fazendas, em espaços precários e [...] seguiam o método individual de ensino" (2000, p.140).

Entre a infinidade de soluções necessárias ao progresso material, educar os brasileiros era condição essencial para a adoção de costumes compatíveis com a produção capitalista e com os empenhos solicitados por uma administração que não primava pela envergadura exigida nos negócios travados internacionalmente, causando mais prejuízos que benefícios aos interesses metropolitanos e coloniais.

Uma das causas do problema incidia no tipo de nomeação feita para a ocupação dos cargos públicos, cujo critério era muito mais o privilégio concedido à nobreza do que mesmo o preparo técnico necessário ao exercício de funções que requeriam um mínimo de conhecimento das práticas comerciais e da política econômica em vigor nas nações adiantadas, fatores que faziam Hipólito da Costa constatar que:

[...] só a prosperidade do povo é quem faz a prosperidade do Governo, que quando se põem obstáculos, e entraves ao progresso, e propagação das ciências, devem ficar tão raros os homens sábios, que quando o Governo precisa deles, de repente, não os acha; e vê-se obrigado ou a lançar mão de um homem instruído, mas sem boa moral; ou de um homem bom, mas estúpido ou ignorante, e quanto menor é o número de gente instruída, 
menos probabilidade há de que o Estado seja servido por homens virtuosos e sábios (CORREIO BRAZILIENSE, 2001, v. I, p. 237).

Hipólito da Costa condenava os privilégios que anulavam qualquer possibilidade de condução favorável dos negócios lusitanos, pois se destinavam os melhores e mais importantes cargos públicos indivíduos completamente inaptos para o cumprimento das funções administrativas. As propostas feitas para diminuir o problema incluíam a aplicação do método do ensino mútuo como uma das formas de alastrar os conhecimentos que permitiriam ao Brasil participar do mundo civilizado, constituindo um corpo de saber já praticado na Europa, precisamente os conteúdos que fizeram da Inglaterra a disseminadora das práticas burguesas pelos novos territórios.

\section{O ensino mútuo}

A preocupação de Hipólito da Costa ao discutir a eficácia do ensino mútuo na Inglaterra e uma possível adoção do sistema no Brasil era pautada na crença de ser um meio para "aumentar a felicidade dos homens". Essa compreensão convergia com o escopo geral de sua obra e reafirmava a necessidade de uma educação política voltada à elite e da qual o sucesso material, político e social do Brasil dependia.

Quanto ao povo, não era desapropriado distribuir-lhe um pouco de instrução naquela quantidade suficiente para organizar a sociedade sob a ótica da modernização. $\mathrm{O}$ Estado seria o maior interessado numa provável elevação moral e intelectual se, de fato, visasse um governo progressista, já que a realidade demonstrava um enorme despreparo, em todos os sentidos, das camadas inferiores da sociedade:

Em toda parte, aonde o povo vive submergido na ignorância, se observa a brutalidade, grosseria e barbaridade [...] Esperamos, que alguém lance os olhos a estas linhas; e se mova a pôr em prática na sua terra, o que tem já produzido tanto benefício neste país; e se houverem pessoas, que tenham assaz coragem e perseverança, para afrontar a oposição, que suas vistas benéficas necessariamente hão de encontrar, a posteridade abençoará a sua memória, quando refletir nos bens que são devidos aos seus trabalhos (CORREIO BRAZILIENSE, 2001, vol. I, p.347-348).

Hipólito da Costa entendia a educação uma parte fundamental no plano de mudanças. O saber, portanto, não poderia ser qualquer conteúdo, veiculado sem propósitos e critérios, mas eficientemente dirigido ao objetivo almejado, no caso, aquele já de domínio dos povos avançados e por eles conscientemente praticado.

A educação no Brasil, no início do século XIX, era regalia da elite. Por outro lado, entre o povo e escravos encontravam-se alguns letrados, apesar de serem em número muito inferior aos da camada dominante. Essa situação se punha um obstáculo ao desenvolvimento de uma mentalidade mais apegada aos fazeres progressistas, na medida em que a ausência do saber elementar - ler, escrever e contar - impedia a maior parte dos indivíduos de conhecerem os grandes avanços científicos que transformavam as matériasprimas rapidamente em mercadorias, sem o tempo e esforço demandado na forma de produção anterior.

Em relação à situação educacional do Brasil, nas décadas iniciais do século XIX, nota-se que Portugal também apresentava um quadro insatisfatório, na medida em que a 
ausência de uma instrução maior e extensiva às camadas intermediárias da sociedade refletia-se no tipo de administradores ao qual o governo português era obrigado a recorrer, como o caso do Conselho de Estado, composto por sujeitos despreparados e escolhidos entre os da classe fidalga sem, no entanto, expressarem o exemplo de capacidade exigida para a função. Argumentava Hipólito da Costa que

Um dos maiores defeitos de administração interna, nas colônias Portuguesas, foi sempre a falta de responsabilidade eficaz, nas pessoas que exercitam autoridade; e isto procede não de que as leis, em teoria, os não façam responsáveis; mas pela distância das colônias à metrópole; por não haver liberdade de imprensa, que publique os abusos dos que governam pela falta de assembléias ou conselhos coloniais independentes da Coroa, que sirvam de contrabalançar o poder dos Governadores. [...] O povo do Brasil tinha seguramente o direito de esperar que estes males se remediassem, com a mudança da Corte para ali; mas a infinidade de cartas que aqui chegam a Londres, todos os dias, dos diferentes portos do Brasil, com repetidas queixas, e narrando fatos particulares, provam que se não tem atendido a este ponto, com a reflexão que lhe requer (CORREIO BRAZILIENSE, 2001, vol. V, p. 123).

O modelo de educação inglês serviu de inspiração a Hipólito da Costa, quando se propôs difundir a instrução no Brasil. A educação dos indivíduos que trabalhariam na administração governamental inglesa começava cedo. Esta medida garantia a manutenção da forma de governo estabelecida em índices aceitáveis de sucesso: "Naquele país [a Inglaterra] todos os nobres se aplicam de tenra idade às letras, a maior parte deles vai às Universidades obter graus acadêmicos e entram em concorrência para os lugares da maior importância" (CORREIO BRAZILIENSE, vol. I, 2001, p. 50).

A educação, na sua visão, juntamente com "os costumes, a ilustração do espírito nos povos, são as únicas garantias da perpetuação da Constituição, e da conservação da liberdade civil" (CORREIO BRAZILIENSE, vol. II, 2001, p. 623), com o poder de contribuir para o desenvolvimento social por poder contar com homens instruídos naquelas matérias fundamentais ao bom curso de um governo:

[...] só a prosperidade do povo é quem faz a prosperidade do Governo, que quando se põem obstáculos, e entraves ao progresso, e propagação das ciências, devem ficar tão raros os homens sábios, que quando o Governo precisa deles, de repente, não os acha; e vê-se obrigado ou a lançar mão de um homem instruído, mas sem boa moral; ou de um homem bom, mas estúpido ou ignorante, e quanto menor é o número de gente instruída, menos probabilidade há de que o Estado seja servido por homens virtuosos e sábios (CORREIO BRAZILIENSE, 2001, v. I, p. 237).

Oferecer instrução a todos não era objetivo do governo português, já que a escolha dos indivíduos que fariam parte da administração recaia sobre os fidalgos, que atuariam, por uma questão de classe, na salvaguarda dos interesses comerciais da Coroa. Este fato foi um determinante na oferta apenas do ensino superior.

Criaram-se cursos superiores nas áreas de maior urgência, em 1808 a Academia Real da Marinha e os Cursos Médicos, primeiramente para a defesa territorial contra invasões estrangeiras e para o atendimento dos integrantes da Marinha e da elite brasileira. Foram abertos também a Academia Real Militar, em 1810, e o de Direito quando o Brasil 
já havia consumado a separação política e visava formar indivíduos para os cargos administrativos do novo império.

Nesse quadro, pensar a educação como resposta necessária ao progresso equivalia à tarefa de difícil concretização, tão remotas eram as chances de sua aplicabilidade no território brasileiro. Restava aos envolvidos com possíveis projetos de nação traçar objetivos que contemplassem a expansão dos conhecimentos até então produzidos pela humanidade como "luzes" a difundir, compromissos assumidos por Hipólito da Costa quando da inauguração do Correio Braziliense:

O primeiro dever do homem em sociedade é ser útil aos membros dela; a cada um deve segundo suas forças físicas e morais, administrar, em benefício da mesma, os conhecimentos, ou talentos, que a natureza, a arte, ou a educação lhe prestou. $\mathrm{O}$ indivíduo, que abrange o bem geral duma sociedade, vem a ser o membro mais distinto dela: as luzes, que ele espalha, tiram das trevas, ou da ilusão, aqueles, que a ignorância precipitou no labirinto da apatia, da inépcia, e do engano (CORREIO BRAZILIENSE, 2001, v. 1, p. 1).

O ensino mútuo seria, então, um facho de luz a iluminar as trevas que encobriam a colônia. Se nem todos os brasileiros poderiam obter um conhecimento elaborado, propalado em escolas destinadas a esse fim, o caminho plausível era a adoção de um método que levasse a instrução a um maior número de indivíduos, mesmo que não significasse o caminho das letras e, sim, o dos fazeres avançados trazidos ao país pelos imigrantes que haveriam de chegar seguidamente, tal qual o Correio advogava e pensava estender como meio de superação do atraso material: "que se deve dar a todos os homens a maior massa de conhecimentos possível, sem interromper as ocupações ordinárias da vida, a que cada indivíduo se destina" (CORREIO BRAZILIENSE, 2001, v. I, p. 347).

Percebe-se que a proposta de ensino mútuo vinculava-se ao conselho que dava aos governantes para que estimulassem os estrangeiros a virem se estabelecer no território brasileiro com medidas favoráveis à adaptação e propriedade das terras. Trariam na bagagem, seguramente, o avançado conhecimento técnico até o momento desconhecido no Brasil, seja nas atividades industriosas ou agriculturáveis, além de participarem do "melhoramento físico da espécie, pelos casamentos de pessoas de diferentes países e constituições" (CORREIO BRAZILIENSE, 2001, vol. VI, p. 228-240).

O objetivo da proposição da vinda de estrangeiros, desejosos de recomeçaram a vida em condições diferentes das experimentadas na Europa, revelava a opinião de que a escravidão representava um óbice ao desenvolvimento material, comprometendo o progresso social. Essa conjectura originou-se em virtude de uma sociedade de trabalhadores livres, vendedores de força de trabalho submetidos às demandas do mercado, realidade oposta ao tipo de trabalho praticado no Brasil. A Inglaterra mais uma vez era seu eixo, contudo as condições de realização da riqueza no Brasil não dispensavam a escravidão, aliás, era ainda a mola propulsora.

O apoio à extinção do tráfico e da escravidão, ainda que lenta e gradual, centrava-se na crítica ao tratado de 1810, cujo teor poderia comprometer o comércio externo brasileiro e exigir uma demanda maior do esforço produtivo de seus habitantes, causando aumento no preço dos escravos, carestia de mão de obra e aumento no valor dos produtos (PERIOTTO, 2004, p. 16). Em vista desses perigos aconselhava que se introduzissem as máquinas: 
[...] em todos os trabalhos aonde elas podem suprir o emprego dos homens; outro é a imigração de gente daquelas partes da Europa, aonde a população tem pouco emprego. A Inglaterra, a França e os Estados Unidos abundam em Engenheiros-Civis e maquinistas; eis aqui, pois, uma classe de gente, que se faz sumamente importante no Brasil; e que deve servir para fomentar o primeiro método, que temos proposto; assim como também a introdução das novas invenções de arados e outros instrumentos de agricultura, que diminuam o uso da enxada, tão comum no Brasil, pelo mau uso do sistema de roças, e em que se empregam mais braços do que seria necessário, adotando-se os instrumentos de agricultura, que diariamente se estão inventando na Europa (CORREIO BRAZILIENSE, 2002, vol. XV, p. 737).

A política e a economia no quadro colonial brasileiro representavam um desafio para a instalação de medidas de melhoramento econômico e social, ainda mais quando a agricultura sofria reveses por falta de indivíduos capacitados, e da ausência dos novos saberes científicos que principiavam a emergir na agricultura. A vinda de colonos europeus, de diversas nacionalidades, traria conhecimentos sobre as técnicas de cultivo predominantes nos países de origem, reforçando a imagem de uma prática onde todos aprendiam com todos e no qual, ao final do processo educativo, se ganharia com o acréscimo qualitativo da ciência.

O remédio benfazejo ao desenvolvimento material seria estimular, entre os estrangeiros, a troca de saberes numa dinâmica que incluísse, além do cambiar de experiências, uma comunhão entre os sujeitos de nacionalidades diversas, promovendo o aumento da população e a criação de uma camada social e espiritualmente mais elevadas:

Temos por várias vezes indicado a necessidade que há de procurar ao Brasil uma população tirada das nações européias; e isto para fins morais, políticos e físicos; porque a não se obrar assim, a raça portuguesa se estragará totalmente com a mistura, tão comum no Brasil, com os negros africanos, cuja compleição e figura viciam o físico das gerações mistas [...] (CORREIO BRAZILIENSE, 2001, vol. I , p. 159).

Da Irlanda, Escócia e Holanda se podem obter excelentes agricultores; da Inglaterra e França, artistas; da Alemanha, mineiros; dos Estados Unidos, colônias inteiras de pescadores, principalmente dos Estados de Conecticut, Rhode Island e Massachussets; homens sábios de todo o mundo; e este grande e precioso aumento de população se pode obter, sem a menor despesa da parte do Governo (CORREIO BRAZILIENSE, vol. XVIII, 2002, p. 376).

A aplicação do ensino mútuo trazia a proposta de contribuir com a miscigenação entre os que adotariam o Brasil por pátria e de purificação dos aspectos físicos e morais das raças, que já se encontravam misturadas, e das razões políticas expressas na busca de um indivíduo mais europeizado. A qualidade e quantidade de conhecimentos que esses povos trariam, resultariam em que:

O agricultor alemão, escocês, italiano, irlandês, húngaro, holandês; cada um edificaria a sua casa à maneira de sua pátria e cultivaria a terra da maneira e com a semente que mais se usasse em seu país; assim no fim de dois ou três anos a combinação de todos estes diferentes experimentos mostraria a toda a colônia qual era o método mais vantajoso ao clima e ao 
terreno; e todos seriam, para assim dizer, mestres uns dos outros, e o que fosse mais bem sucedido, esse seria o mais imitado por seus vizinhos (CORREIO BRAZILIENSE, 2001, vol. VI, p. 238- 239).

Se a Europa se modernizava em célere movimento, no Brasil a realidade era bem diversa. O ensino mútuo, na proposição de Hipólito da Costa, viria a suprir as demandas de uma sociedade que tinha na mão de obra escrava a forma de produzir riqueza e, ainda na condição de colônia submetida às imperiosidades do interesse português, não participava de nenhuma ação progressista que promovesse um desenvolvimento material que avançasse além dos limites da exportação de matéria-prima e dos recursos naturais e de alguns manufaturados como o açúcar, o charque e o fumo.

$\mathrm{O}$ trabalho livre executado por europeus era uma alternativa à escravidão e estimularia, por imitação, "O colono rústico do Brasil" a reproduzir os métodos dos vizinhos estrangeiros. A aplicação do trabalho estrangeiro se recebesse o auxílio necessário do governo em pouco tempo libertaria o Brasil da escravidão, cuja continuidade "era tão contrária aos princípios do direito natural e da constituição moral do homem" (CORREIO BRAZILIENSE, 2002, vol. VI, p. 238- 239), expressando as mudanças no debate sobre a pertinência do trabalho escravo frente ao trabalho livre sob a ótica da justiça e da moralidade.

Com a independência, a nova realidade passou a requisitar indivíduos habilitados para compor a estrutura administrativa, pois não se podia mais recolhê-los entre os portugueses, mas esse fato não incentivou o poder público a oferecer um tipo de educação mais elevada, bastavam os conhecimentos elementares, suficientes para a ordenação do Estado e a obediência estrita ao novo governo imperial: "Nessa perspectiva, a instrução como um mecanismo de governo permitiria não apenas indicar os melhores caminhos a serem trilhados por um povo livre, mas também evitaria que esse mesmo povo se desviasse do caminho traçado" (FARIA FILHO, 2000, p.137).

A massa de homens que ocupavam o território brasileiro era inculta. A instrução proporcionada pelo método de ensinar uns aos outros, sem grandes custos ao erário público, poderia ser de grande valia no momento de difundir a instrução que transformaria o "menino" num "cidadão útil, obediente e morigerado' (CORREIO BRAZILIENSE, 2001, v. 1, p. 349). As reformas necessárias ao estabelecimento de práticas progressistas ordenavam a construção de um indivíduo que mais colaborasse com o projeto burguês em implantação do que obstasse a consolidação de novas regras sociais definidas pelo movimento histórico do capitalismo, destinadas ao mundo até então colonial.

\section{Conclusão}

Reafirma-se que o debate realizado por Hipólito da Costa não trazia a educação como questão fundante no quadro de desenvolvimento econômico e social que traçava para o Brasil, e no qual postulava por medidas reformistas que alcançassem o sistema de governo e de administração dos negócios coloniais. Todavia o jornalista também não a rejeitava como um dos momentos importantes na realização das propostas reformistas, pois a convicção de que um governo forte era causa da riqueza de um povo fazia considerá-la um dos meios adequados à direção equilibrada e competente dos interesses de Estado, portanto fundamental na formação de indivíduos em condições de entender as necessidades do Brasil e de adotar as medidas coerentes à realidade.

A verdade é que, no alvorecer do século XIX, era praticamente impossível subtrairse ao arrojo transformador incitado pelas forças sociais em desenvolvimento. Por muito 
tempo Portugal afastou da sua colônia mais rica, pelo crédito da força e opressão, o poder da influência do ideário burguês fechando seus portos, proibindo a entrada de estrangeiros no território, confiscando e destruindo tudo que remontasse à aquisição de conhecimento nascido sob o escudo das Luzes e que significasse o desaparecimento das ideias que representava. A vinda da família real e da corte rompeu em definitivo com esse quadro, no qual qualquer pretendido retorno à condição de colônia suscitaria conflitos e desordens e o esgarçar do território nacional estaria entre as mais sérias consequências.

Se a ausência de um clima propício ao debate de ideias e procedimentos modernos havia comprometido a compreensão dos brasileiros sobre as possibilidades reais de mudanças, a percepção do significado de suas vidas para a metrópole, dos seus fazeres e da riqueza que produziam não se conformou à tese de que o destino do Brasil estaria indelevelmente ligado ao dos portugueses. As diferenças se acentuavam, os privilégios corriam à solta para os lusitanos, as tarifas exorbitavam ao limite do bom senso econômico. Enfim, Hipólito foi correspondido nas suas pretensões pelas circunstâncias da época, nas quais os brasileiros se viam enleados na difícil escolha de manter-se colônia ou de provar da liberdade.

O caráter educativo inerente ao conteúdo do Correio Braziliense confirma-se, então, nos desdobramentos da luta por maior liberdade e participação nas lidas governamentais e atingiu seu ponto alto com a independência do Brasil, momento em que o jornalista encerra a missão de açular as forças do passado e de contribuir para a entrada das ideias liberais no atendendo a necessidade de "ordenação do poder nacional".

Nesse conjunto de intenções e ações programáticas definidas com antecipação, o debate proclamado no Correio Braziliense aponta para um aspecto basilar à compreensão do seu significado perante a época, o de ter sido um produto de circunstâncias definidas pelo movimento da história, acelerado pela compreensão de que os interesses brasileiros em jogo não se identificavam mais com os limites econômicos e culturais do Absolutismo português, mas com os da burguesia internacional.

A tarefa de Hipólito, desde sempre, foi contribuir para o estabelecimento das bases de formação da burguesia brasileira, alijando a aristocracia e os conteúdos inapropriados que a ela pertenciam. O Correio, neste projeto, constituiu-se um auxiliar poderoso, tanto por sua organização textual, sistematização das ideias e da exposição detalhada da prática social que conferia à Europa um desenvolvimento sem igual, exatamente o mesmo que ambicionava predominando no Brasil.

O ensino mútuo, o "ensinar tudo a todos", o trocar conhecimentos entre indivíduos das diversas nacionalidades que poderiam ser convidados a participar da construção do "novo Império", mesmo sob o estatuto português, mas com sede no Brasil, seria um caminho seguro na criação das condições fundamentais à civilidade burguesa. Os braços escravos tenderiam, por força de quem domina a técnica, dar lugar a quem sabia manejar as rédeas do progresso plantando as melhores sementes e convivendo com os demais sob as regras do conhecimento que produz lucro e poder.

No bojo das ideias que objetivavam a ascensão material do Brasil, reafirmam-se os termos com os quais iniciou seu jornal: "O indivíduo que abrange o bem geral duma sociedade, vem a ser o membro mais distinto dela: as luzes, que ele espalha, tiram das trevas, ou da ilusão, aqueles, que a ignorância precipitou no labirinto da apatia, da inépcia e do engano" (CORREIO BRAZILIENSE, 2001, vol. I, p.1). Ao compreender as causas que se opunham ao desenvolvimento como inerentes a uma forma de governo ultrapassada e a práticas materiais do passado, Hipólito da Costa perseverava na divulgação dos conhecimentos, histórica e cientificamente mais avançados, para a elevação da instrução 
dos brasileiros, na qual a proposição do ensino mútuo despontaria como um dos componentes do projeto civilizador que difundiu no início do século XIX.

\section{Referências}

CORREIO BRAZILIENSE OU ARMAZÉM LITERÁRIO. v. 1 a 8. São Paulo, SP: Imprensa Oficial do Estado; Brasília, DF: Correio Braziliense, 2001. (Edição fac-similar).

CORREIO BRAZILIENSE OU ARMAZÉM LITERÁRIO. v. 9 a 25 e v. 30. São Paulo, SP: Imprensa Oficial do Estado; Brasília, DF: Correio Braziliense e, 2002. (Edição fac-similar).

FARIA FILHO, Luciano Mendes. Instrução Elementar no século XIX. In: LOPES, Eliane Marta Teixeira; FARIA FILHO, Luciano Mendes; VIEIRA, Cynthia Greive Veiga. (Orgs.). 500 anos de Educação no Brasil. 2 ed. Belo Horizonte: Autêntica, 2000.

LEME, Marisa Saenz. Hipólito da Costa e a Construção da Independência no Brasil. In: Intérpretes do Brasil: cultura e identidade. Orgs. Gunter Axt e Fernando Schüller. Porto Alegre, RS: Artes e Ofícios, 2004, p. 37-48.

PERIOTTO, Marcília Rosa. O papel da imprensa no processo de construção da nação: a "vocação pedagógica" do Correio Braziliense. REVISTA HISTEDBR On-line. UNICAMP. Campinas, n. 16, p. 61-83, dez. 2004.

SECO, Ana Paula. Um olhar sobre a educação na colônia: os viajantes estrangeiros. VII SEMINÁRIO NACIONAL DE ESTUDOS E PESQUISAS - HISTEDBR. Universidade Estadual de Campinas, Campinas-SP, 2006.

TENGARRINHA, José. História da Imprensa Periódica Portuguesa. Lisboa: Portugália Editora, 1965.

\footnotetext{
1 Este artigo é parte do Relatório de Pesquisa do Estágio Pós-Doutoral - "Hipólito da Costa e o Correio Braziliense: a educação política da elite brasileira no início do século XIX", realizado na Universidade Federal de Minas Gerais nos anos de 2007 a 2009, sob a supervisão do professor Luciano Mendes de Faria Filho e auxílio-bolsa CNPq. Outra comunicação foi apresentada no VIII Seminário Nacional de Estudos e Pesquisas - HISTEDBR, na Universidade Estadual de Campinas, 2009, Campinas-SP.
}

Recebido em: $\quad 12 / 02 / 12$

Aprovado em: 20/03/12 